\title{
National Spherical Torus Experiment (NSTX) Torus Design, Fabrication and Assembly
}

\author{
James H. Chrzanowski, Charles Neumeyer, Philip Heitzenroeder, George Barnes, Mike Viola, \\ Princeton Plasma Physics Laboratory, Princeton, NJ 08543 USA, Brad Nelson, Paul Gorenson, Oak \\ Ridge National Laboratory, Oak Ridge, Tn USA, and the NSTX Group *
}

\begin{abstract}
The National Spherical Torus Experiment (NSTX) is a low aspect ratio spherical torus (ST) located at Princeton Plasma Physics Laboratory (PPPL). Fabrication, assembly, and initial power tests were completed in February of 1999.
\end{abstract}

The majority of the design and construction efforts were constructed on the Torus system components. The Torus system includes the centerstack assembly, external Poloidal and Toroidal coil systems, vacuum vessel, torus support structure and plasma facing components (PFC's). NSTX's low aspect ratio required that the centerstack be made with the smallest radius possible. This, and the need to bake NSTX's carbon-carbon composite plasma facing components at 350 degrees $C$, was major drivers in the design of NSTX.

The Centerstack Assembly consists of the inner legs of the Toroidal Field (TF) windings, the Ohmic Heating $(\mathrm{OH})$ solenoid and its associated tension cylinder, three inner Poloidal Field (PF) coils, thermal insulation, diagnostics and an Inconel casing which forms the inner wall of the vacuum vessel boundary. It took approximately nine months to complete the assembly of the Centerstack. The tight radial clearances and the extreme length of the major components added complexity to the assembly of the Centerstack components.

The vacuum vessel was constructed of 304-stainless steel and required approximately seven months to complete and deliver to the Test Cell. Several of the issues associated with the construction of the vacuum vessel were control of dimensional stability following welding and controlling the permeability of the welds. A great deal of time and effort was devoted to defining the correct weld process and material selection to meet our design requirements.

The PFC's will be baked out at 350 degrees $C$ while the vessel is maintained at 150 degrees $C$. This required care in designing the supports so they can accommodate the high electromagnetic loads resulting from plasma disruptions and the resulting relative thermal expansions between the PFC's and the vacuum vessel on which supports are attached.

This paper will provide a brief review of the issues associated with the design, fabrication and assembly of the NSTX Torus system including those outlined above.

\section{INTRODUCTION}

NSTX achieved its first plasma in February 1999 and began experimental operations in August 1999. Figure 1 shows the NSTX Test Cell towards the end of the assembly phase. Princeton Plasma Physics Laboratory constructed the device in collaboration with Oak Ridge National laboratory, Columbia University, and the University of Washington at Seattle.

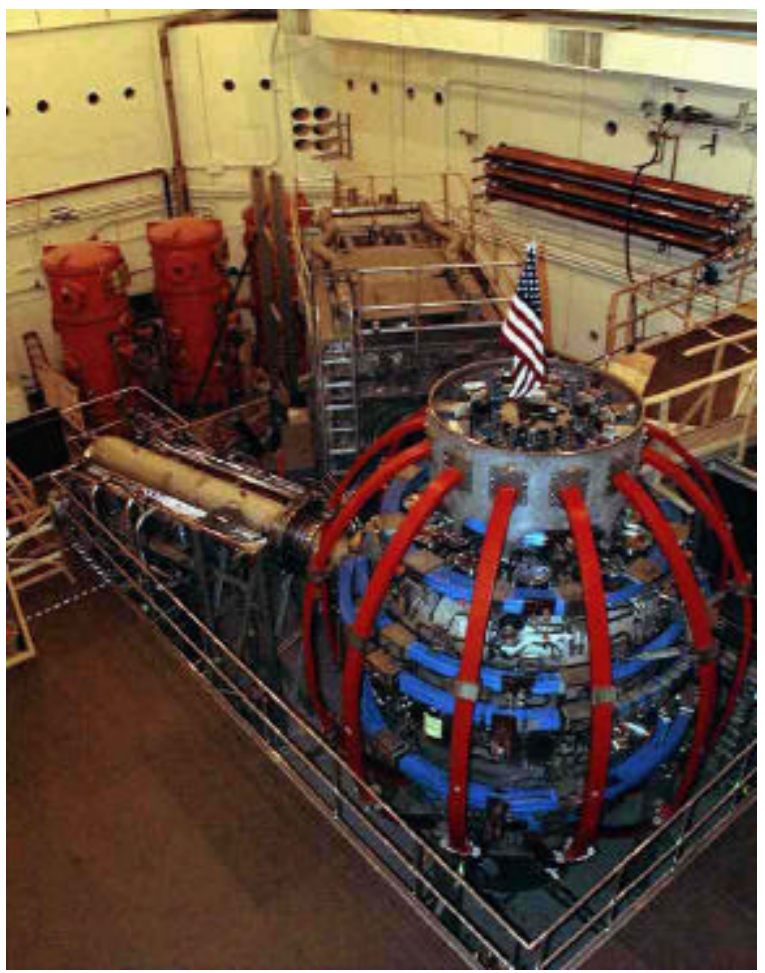

Figure 1. ...NSTX During Final Construction in January 1999

\section{DESIGN OVERVIEW}

A cross section of NSTX is shown in Figure 2. The centerstack assembly in Figure 3 is the most complex and critical component of NSTX. It was a modular design so that it can be easily removed for future upgrades or maintenance. The centerstack consists of the following elements:

- Inner TF Leg Bundle is the innermost element of the CS, consisting of (36) copper bars for the central legs of the toroidal field (TF) system.

1. Surrounding the TF bundle is the Ohmic Heating $(\mathrm{OH})$ solenoid. The $\mathrm{OH}$ is wound on a $3 \mathrm{~mm}$ thick stainless steel tension tube that supports the $\mathrm{OH}$ coil while permitting axial thermal expansion. The 962 turn winding is arranged in 4 layers, wound 2 in hand to provide 8 parallel cooling paths in minimize thermal gradients (and shear stresses) during cool down 


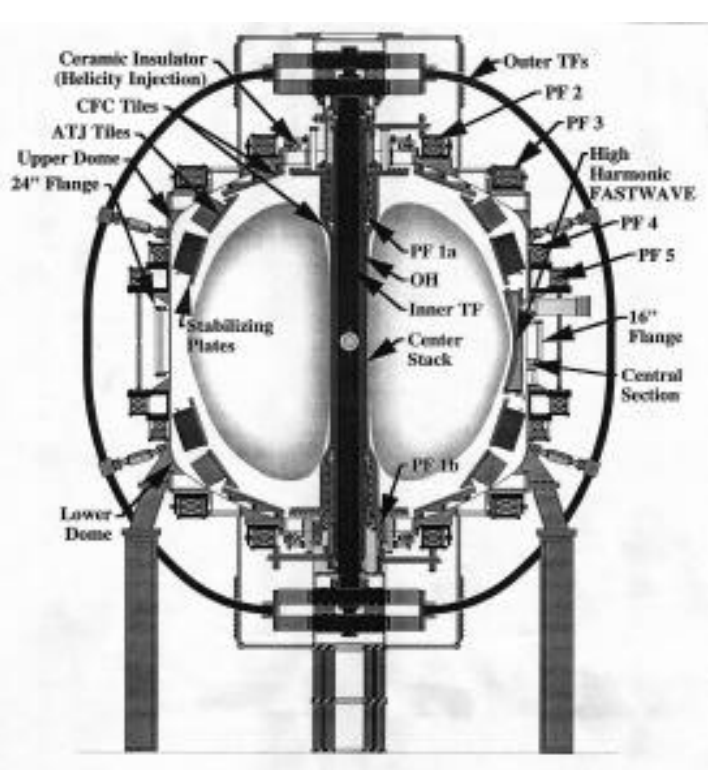

Figure 2- Cross Section of NSTX

2. Shaping field (PFla) coils are located concentric to the solenoid near the ends. Provides field shaping necessary to form NSTX's plasma geometry.

3. Single coil $(P F 1 b)$ is located on the lower end of the CS assembly. It is used to form the magnetic geometry required for Coaxial Helicity Injection (CHI) experiment.

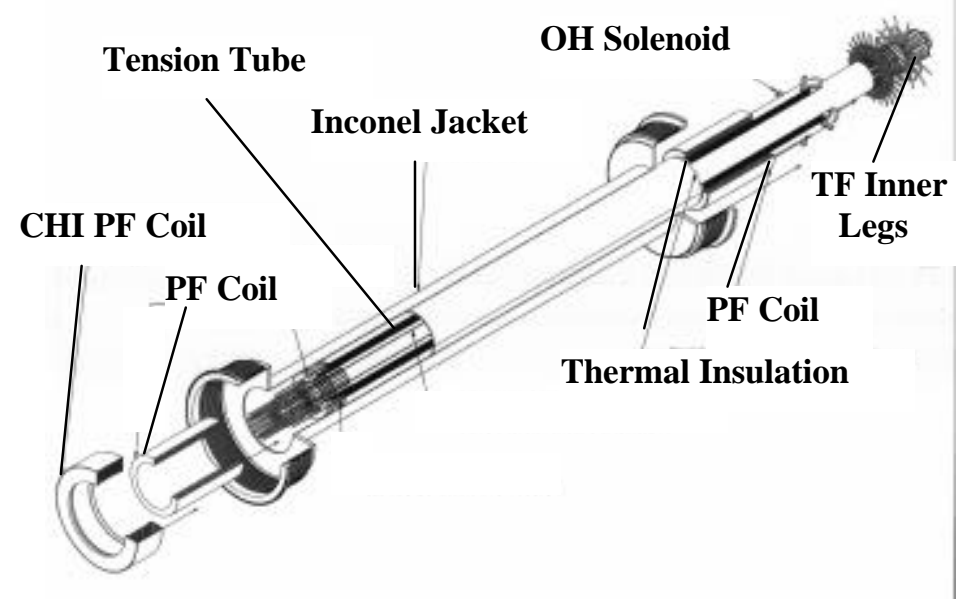

Figure 3. Centerstack Components.

4. Magnetic diagnostics, including flux loops, Rogowski coils and thermocouples are installed on the surface of the $\mathrm{OH}$ coil.

5. A thermal insulation jacket was supplied by Microtherm Inc. of Maryville, Tn. It over-wraps the $\mathrm{OH}$ and $\mathrm{PF}$ coils, and the magnetic diagnostics to protect them from heating. The CS casing can reach temperatures in the range of $600 \mathrm{C}$ during operation and bakeout.

6. The centerstack casing made of $4 \mathrm{~mm}$ Inconel, surrounds the assembly and forms the inner wall of the vacuum vessel.
7. Graphite and carbon-carbon tiles protect the CS casing wall.

There (12) Outer TF coils that are connected to the Inner TF bundle via flexible laminated copper straps. This accommodates the relative motion between the CS and Pouter TF Legs. Figure 4 shows then top of flexible bus connections between the CS and Outer TF coils.

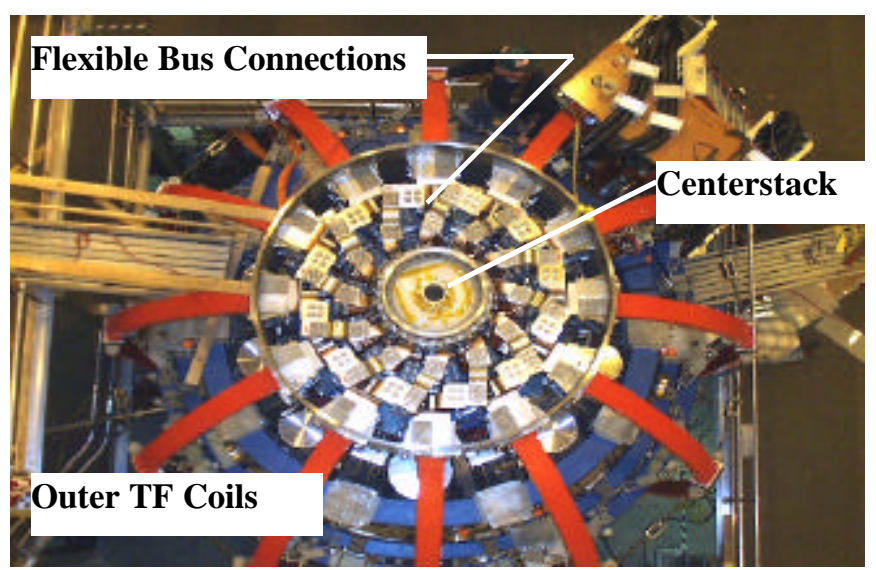

Figure 4- View showing TF Flexible Bus Connections

\section{CENTERSTACK DESIGN SOLUTIONS}

The performance criteria for low aspect ratio ST's requires compact, high performance designs for all of the centerstack components. High current densities, high temperature rises, thermal expansions and stresses were all design issues for the centerstack. Assembly clearances between the CS components were challenging but attainable. The straightness and circularity tolerances had to be chosen carefully to ensure that the components could be manufactured and at a reasonable cost. Some of the design solutions used for the Centerstack included:

A. The coils were structurally decoupled as much as possible. This decision was made to minimize shear stresses between coils, to provide simple and easily analyzed load paths, to permit parallel fabrication of the TF, OH and PF CS coils, and to improve failure recovery.

B. The TF CS legs were shear bonded by the turn-to-turn insulation. This decision eliminated the need for shear keys. A torque reaction structure was also added to reduce shear stress levels.

C. Structures and bus connections were designed to permit free thermal expansions to avoid excessive thermal stresses.

D. The current densities for the centerstack TF and $\mathrm{OH}$ coils were designed such that the maximum temperature of the coils was below $100 \mathrm{C}$. With this approach, water-cooling was used, and the insulation scheme candidates were broader. 


\section{DESIGN \& FABRICATION ISSUES}

This section will only address several of the design and fabrication issues associated with the Torus system.

\section{A. Ohmic Heating (OH) Solenoid}

The $\mathrm{OH}$ solenoid was wound directly onto a stainless steel tension tube which was used as both the winding mandrel and supporting structure. A Belleville washer assembly provides an axial preload and upward load reaction path to the solenoid but allows for thermal growth.

The $\mathrm{OH}$ coil was wound with 4 layers, two in hand to:

1. Shorten the flow path to avoid high water flow velocities.

2. Permit the coil to wound with joints only between layers with commercially available lengths.

B. A layer-to-layer joint was developed which would avoid annealing of the CDA-10700 conductor while maintaining strength. The coil copper is stressed to 142 Mpa (20.5 ksi) during operation. The overlapped surfaces are pre-tinned with $96 \%$ tin/4\% silver solder. The ends of the conductor are TIG tack welded with a short 7-109 sec. Braze time. Tests indicate a joint static strength of 235 Mpa (34 ksi) and a fatigue life of $~ 400,000$ cycles with a stress range of $138 \mathrm{Mpa}(20 \mathrm{ksi})$. Figure 5 shows the typical OH Layer-to-Layer Joint.

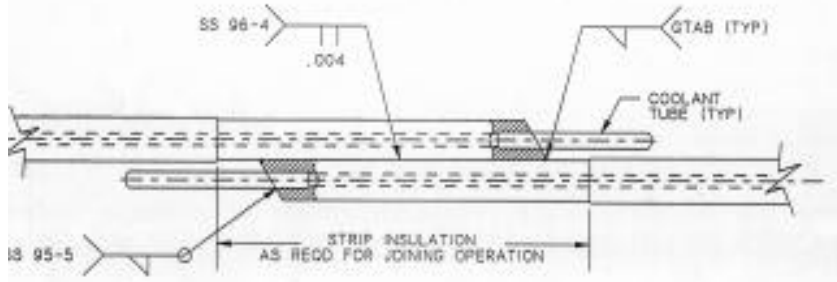

Figure 5- Typical OH Layer-to-Layer Joint

\section{Vacuum Vessel}

The NSTX vacuum vessel was fabricated by "Process Systems International of Massachuttes. The vessel was constructed in sections (domes, straight section) using 304stainless steel. The sections were then joined and flanges added by using GTAW welding process with ER316H welding wire. Once delivered, PPPL completed the construction with final machining of the end flanges and welding of the PF support ribs and heating/cooling lines to the vessel walls. The most significant fabrication issues were control of dimensional stability following welding, and controlling the magnetic permeability of the welds. Internal support structures had to be utilized to help control the dimensional stability. However even with the internal structure the domes arrived slightly distorted, out of tolerance, resulting in custom modifications to the internal PFC support hardware. Maintaining a reasonable permeability of the welds was the most difficult problem to address. An extensive program was undertaken jointly by PPPL and PSI to develop an optimum weld process. This along with the decision to use ER316H welding wire enabled PSI to achieve desirable permeability values between 1.2 and $2.0 \mu$.

\section{Centerstack Assembly}

The assembly of the Centerstack was completed in a ninemonth period. The individual components were fabricated by outside vendors, then delivered and assembled together at PPPL. The Centerstack was delivered to the Test Cell in October 1998. One of the issues with assembly was the close clearance tolerance between components. The nominal clearance between assemblies was quite small. The space between the Inner TF bundle and $\mathrm{OH}$ solenoid was only $3.3 \mathrm{~mm}(0.13 \mathrm{in}$.), as was the clearance between the thermal jacket and Inconel wall. This along with the excessive lengths of 5.7 meters (18.6 feet) combined to make the assembly of the CS components a critical phase of the program. Figure 6 shows the installation of the $\mathrm{OH}$ solenoid over the Inner TF bundle.

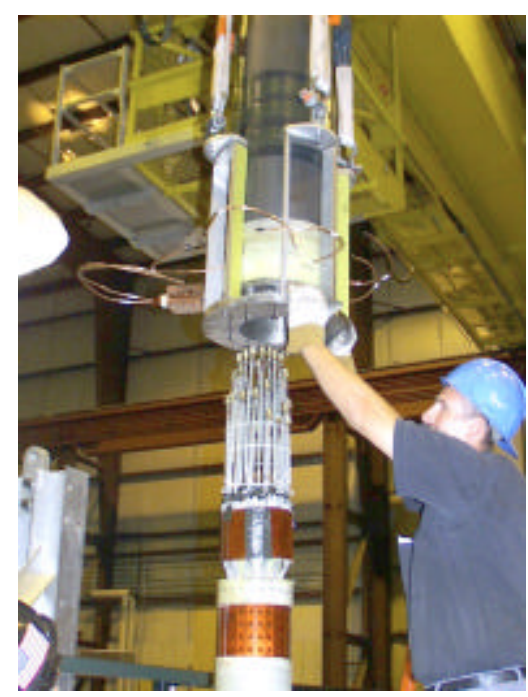

Figure 6- Installation of $\mathrm{OH}$ Solenoid

\section{TORUS ASSEMBLY}

The assembly of the NSTX torus was accomplished in a 3month period. During that period all of the major components including the vacuum vessel, PF coils, Centerstack Assembly, Outer TF Leg Assemblies and invessel PFC's were installed. The vacuum vessel, centerstack assembly and external PF coils arrived in the NSTX Test Cell in October. At that the time the PF coils were mounted to the vacuum vessel and the assembled components installed as one unit. Once the vacuum vessel was placed in position, the outboard Divertors were installed followed by the Centerstack assembly. The installation of the Centerstack assembly as shown in Figure 7 only took several hours to complete. Since the initial installation, the CS has been removed/reinstalled during a recent maintenance period. The ease at which this can be accomplished supports this type design for future upgrades and repairs. The last of the Outer TF coil assemblies was installed in December 1998. 


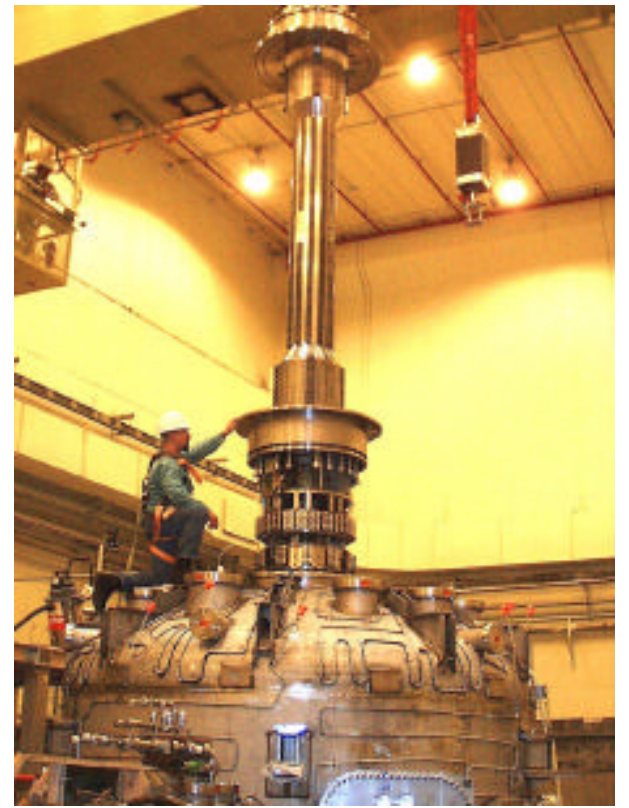

Figure 7- Installation of Centerstack Assembly

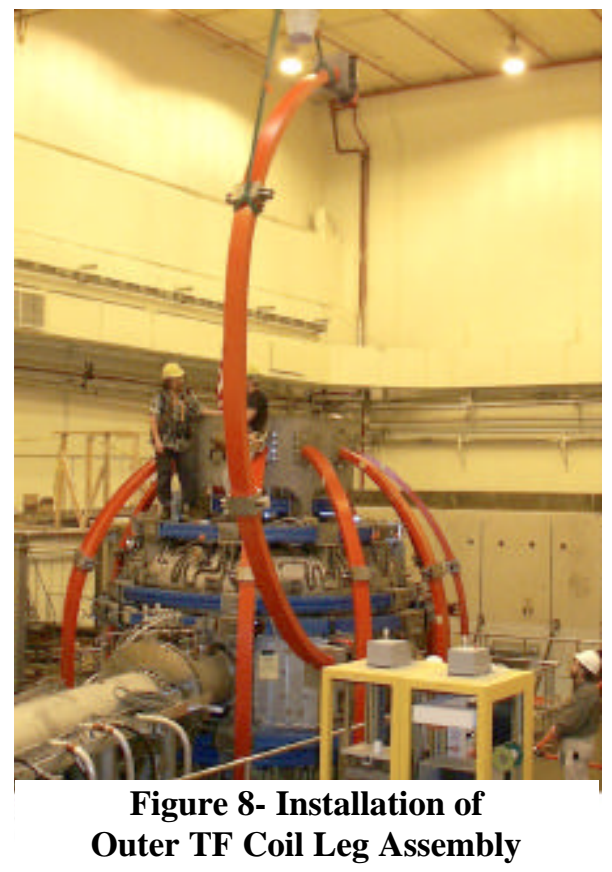

VI. SUMMARY

The need for a low aspect ratio in NSTX required compact, high performance coil and structure designs. The design choices made by NSTX included structurally independent coils, "slide together" assembly of the centerstack, use of flexible electrical connectors, and structures, which can accommodate the thermal growth. Manufacturing clearances and tolerances for the torus components were challenging but achievable. The TIG braze/soldered joint developed for the $\mathrm{OH}$ coil; avoids annealing and exhibits good static and fatigue strength. The assembly of the major torus components went together smoothly with very few issues. The Centerstack Assembly is the most critical and difficult component to fabricate for NSTX. NSTX has demonstrated since "First Plasma" that the centerstack can be easily removed and reinstalled with little difficulty. This will become extremely useful for future upgrades or repairs. The "First Plasma" goal was successfully achieved in February 1999. Following a maintenance period in which the remaining PFC's were installed, NSTX begun experimental operation

\section{ACKOWLEDGEMENTS}

The authors would like to thank the entire NSTX team for their contributions to this work. We are particularly indebted to Mr. John Citrolo and Mr. John Spitzer for their critical contributions to the engineering of the NSYX magnets and Mr. Lew Morris and Mr. Joe Rushinski for their many contributions to the design concepts and outstanding preparation of the computer aided design drawings. One additional thanks goes out to all of the engineers, senior lab and technicians who helped to fabricate and assemble the NSTX device.

\section{REFERENCES}

[1] Chrzanowski, James H. "National Spherical Torus Experiment Centerstack Research and Development Final Report”, Report No. 13-970430-JHC; April 1997

[2] Neumeyer, C. et al; "Engineering Overview of the National Spherical Torus Experiment (NSTX)" IEEE/NPSS $17^{\text {th }}$ Symposium on Fusion Engineering, 1997.

[3] Heitzenroeder, Philip, et al "Chosen Solutions to the Engineering Challenges of the National Spherical Torus Experiment (NSTX) Magnets" $16^{\text {th }}$ International Conference on Magnet Technology, Ponte Vedra Beach, Fla. October 1999

[4] Chrzanowski, James H., et al; "National Spherical Torus Experiment (NSTX) Centerstack Design and Assembly" IEEE/NPSS $17^{\text {th }}$ Symposium on Fusion Engineering, 1997.

\footnotetext{
* This work is supported by the U.S. Department of Energy under contract DE-AC02-76-ChO3073
} 